\title{
Review of Mark Andrejevic (2020). Automated Media
}

\author{
Abingdon and New York: Routledge. 180 pp. ISBN 9780367196592 \\ (Hardcover)
}

\section{Adam Matthews $^{1}{ }^{\mathbb{C}}$}

Accepted: 17 January 2022 / Published online: 26 January 2022

(c) The Author(s), under exclusive licence to Springer Nature Switzerland AG 2022

Keywords Automation $\cdot$ Post-subjectivity $\cdot$ Data $\cdot$ Machine learning $\cdot$ Media $\cdot$ Preemption · Postdigital

\section{Introduction}

Data, machine learning, and artificial intelligence have produced new forms of nonhuman agency in that more and more tasks are automated or being predicted to be automated. Such automation is the focus of Mark Andrejevic's Automated Media (2020a). 'When an algorithm decides what items to feature in your social media news feed or what music to play next, or if a 'neural net' generates and compares controlled experiments to determine what ad you are most likely to respond to, that's automation' (29). Platforms and their data claim to know us better than we know ourselves, examples include Netflix knowing our taste in movies, Spotify deciding our next album listen, and our phones telling us how to get home (142).

Andrejevic delves into these phenomena with an insightful and critical analysis of how more and more cognitive processing is being offloaded to machines. He provides a framework for thinking about automated media 'understood as communication and information technologies that rely on computerized processes governed by digital code to shape the production, distribution and use of information' (29). Despite the title of Automated Media and looking at social media in some detail, the book offers an approach to automation for all aspects of society and is applicable to a wide readership.

\section{Is Automation Different This Time?}

Wajcman (2017) asks if automation is going to be different this time with the prospect of digital technology and artificial intelligence leading to the automation of many aspects of society. The question of being different this time is important,

Adam Matthews

a.matthews.3@bham.ac.uk

1 University of Birmingham, Birmingham, UK 
as there has been a long history of automation and sociotechnical imaginaries, predicting and influencing the future. Much of the present and past discourse has been centred on the economics of machines taking the jobs of humans and what this means for society. Famously, Keynes (2010) in 1930 called for optimism for the opportunities that new technologies would afford - higher standards of living for all and a working week of no more than 15 hours, with the remainder of the time dedicated to leisure and culture.

Wajcman (2017), in asking if things will be different this time, calls for us all to engage in what the future might be like and not leaving it to the hyped and homogenous view provided by Silicon Valley technologists and investors. Andrejevic (2020a) goes beyond the imaginary of a robot taking your job to a machine and the owners of those machines taking away your subjectivity. The introduction of the book grounds our current challenges of automation historically in making the point that while automation in the twentieth century West was offloading physical labour with industrialisation in the form of the factory, the challenge of the twenty-first century is the automation of the subject, both cognitively and behaviourally.

Andrejevic fuses the technological and political (something technologists and politicians seem to rarely do) to analyse this new wave of automation fuelled by digital monitoring, machine learning, and algorithmic decision making. This includes consumption, production, politics, and security. Buying a product or reading a newspaper no longer sees the product or publication leave the factory or printing press to be consumed anonymously, the artefact and its consumers are tracked digitally, and the data is fed back into the production process. This results in many forms of automation which the author argues is usually focused on efficiency, productivity, and profitability. 'If, in the industrial era, the promise of automation was to displace manual labor, in the information age it is to pre-empt agency, spontaneity, and risk: to map out possible futures before they happen so objectionable ones can be foreclosed and the desirable ones selected.' (Andrejevic 2020a: 9)

Many have focused on automation as automating the tasks of the employee. Andrejevic goes further, stating that if security, law enforcement, politics, and education (in fact every facet of public and private life) are commercially automated, we will see not just the displacement of jobs for the liberation or oppression (depending on your point of view) of humans but their displacement. 'The machines won't free us up to fish or philosophize - they will do these in our stead - and according to the priorities set by those who own and control the automated infrastructure. This is automation not as liberation but as total control.' (Andrejevic 2020a: 18)

One of the author's central concerns is the removal and automation of subjectivity and judgement of the individual within a quantified, automated, and postsubjective future where everything is digitally tracked and processed across all aspects of society. According to Andrejevic, the scope of technological solutionism is reaching all areas of public life with the aims of efficiency, cost control, and objectivity. This is termed a 'post-political technocracy'. 


\section{The Many Faces of Automation}

Chapter 2 looks at the 'Bias of Automation'. This topic has caused some disagreement between Andrejevic and a fellow reviewer of the book (Rettberg 2020). Rettberg points out that the book misses out a huge and well-established literature on the bias of objective data and specifically the bias outcomes of artificial intelligence in decision making (i.e., Noble 2018). Rettberg's argument points to critical perspectives on objectivity being socially constructed (Gitelman 2013). Andrejevic (2020b) has responded, stating that the bias he is writing about is the bias of the medium (rather than the bias of 'objective' data); the newspaper is different to the radio, and the radio is different to the Internet, with different affordances as well as similarities (Matthews 2021).

The bias of the medium, Andrejevic (2020b) points out, carries its own architecture and bearing upon the social, reconfiguring the way information is stored, shared, and processed within the economic and social systems of the present. Global (social) media platforms then offer affordances ideal for information capitalism: speed, ubiquity, and long-distance control. Big Tech would not function without such automation at scale. Andrejevic goes on to describe this as a post-social bias in automation which removes social action and political debate, reducing them to sorting and correlating rather than judgment and subjectivity. The discourse and hype around such possibilities is often centred around a human inability to process large amounts of available information and such processing left to machines. Andrejevic (2020b) makes the argument that there are trade-offs to be made in the choice of automation in society and not merely that humans are inferior to machines at processing information.

Such scale and ubiquity, it is argued, make possible the concept of pre-emption in identifying risk or issues before they even happen. An example used is products being sent by Amazon to customers without them placing an order - the claim is that data reliant platform companies know what you want before you do, thanks to data collected and processed on your behaviour. Pre-emptive actions rely on causal explanations for that data analysis. This is described as the antitheses of experience or any attempt to explain the cause and effect - it just happens. The scale of today's data collection is described as environmental governance using Foucault's concept of environmentality with the prevalence of devices that capture data on us resulting in 'comprehensive monitoring' across and transcending boundaries of work, leisure, and home life making data capture and automation 'frameless'.

Chapter 3 moves on to look at the automation of culture. The author does not deny that there has always been a flood of information at our disposal and that selecting and curating cultural information and interests have been outsourced to others — schools, publishers, academics, journalists, editors, DJs, critics etc. Andrejevic explores the filter bubble and echo chamber effects of social media, which are presented by many as an individual simply consuming information that they agree with resulting in divisive politics and culture wars. Andrejevic is sympathetic to this convenient and popular way to explain a divisive and politically divided society, yet he goes further to explore the impact of automation on events such as the election of Donald Trump in the USA and anti-vax stories during the Covid-19 pandemic. 
Paradoxically, the Internet and associated technologies give us access to a huge amount of information, allowing for (in theory) well informed, politically aware citizens. Yet how much information is too much?

Andrejevic questions whether the wider discourse of automation as conceiving the world as objective and quantifiable has reduced individuals' and society's ability and desire to understand the perspectives of others by seeing them in binary terms, as right or wrong. Those who own and design the huge social media infrastructures that we now inhabit are not motivated by social cohesion, democracy, and balanced political debate. Collective citizenship is not actively pursued by Big Tech, although it might be a marketing strategy; a consuming, self-interested, arguing individual makes for more online content and profit. The individual nature of contemporary web technologies works in perfect symbiosis with neoliberalism as individuals carve out their own 'brand' and 'sell' one's own beliefs and attitudes in competitive rather than collaborative ways.

When humans are not capable of processing the growing amount of information, then machines it is often said are the only answer which further removes subjectivity and reduces nuanced debate. This results in social de-skilling and the inability to engage with difficult political issues beyond binaries such as right and wrong, good and evil, outraged and celebrated. Andrejevic further argues that exercises in judgement are being eroded and the issue is not the lack of bandwidth to process a flood of information but a crisis of judgement enabling representation, reflection, and deliberation. 'The ready response, in either case, is to let the machines sort it out.' (Andrejevic 2020a: 69)

Chapter 4 goes into detail on pre-emption which sees automated decision-making act before and/or just as an incident occurs in real time, aided by a network of online data, cameras, and sensors which attempts to provide complete surveillance. This surveillance then observes and looks for anything that deviates from the 'norm'. Public and private networks go from documenting public life to predicting and pre-empting it. This is termed a post-Panoptic future which takes Bentham and Foucault's concept of the Panopticon from you may be watched to you are being watched, recorded, and analysed.

Andrejevic (2020a) uses law enforcement as an example of the short-term nature of pre-emption which identifies risk and law breaking as it happens but ignores potential causes such as structural inequalities. Pre-emption is not about prevention but identifying patterns and total surveillance of society. The question, therefore, is no longer why a crime happens, but when and where. Public policy questions are further complicated when data is collected and owned by a complex network of public and private actors.

Chapter 5 uses the example of 'The Operational City'. The term operational speaks to the way in which the bias of automation is used in the way the city works and operates. The city is an ideal place for such a 'cyber-capitalist imaginery', a densely populated urban environment of workers, consumers, infrastructure, and culture with lots of data to be captured.

As a physical space becomes permeated by commercial sensing systems, it is transformed into the interface for automated data collection and thus for 
the accumulation and privatization of data. Once equipped with proprietary sensor networks, public space can be equipped with an overlay of privatization, following in the footsteps of the Internet. (Andrejevic 2020a: 94)

The Operational City is control and governance by a network of private interests enabled by Internet of Things sensors to collect data for control and analysis. Such data capture follows the same trend of neoliberalism and commercialization as the Internet itself. Access to information can be bought and sold. Public spaces then become overlayed and managed by private entities. Apps can influence where traffic goes through a city. City infrastructure turns into a complex mix of public and private ownership and governance. The city is just one example of the principle that neoliberal efficiency and marketisation work in perfect harmony with data collection, automation, and operations. One can then easily extend the principle to schools, universities, and other public spaces.

A common justification for such 'objective', data-driven automation is that traditional politics has failed, so a technical capture of all data can lead to technocratic solutions. The premise here is that if humans are incapable of processing all of the information available, then they are not able to make political decisions or judgements as elected politicians or citizens - Google and other platforms complete our sentences, and the next step is to decide where our political judgements should be. 'The attempts to bypass the political and to dispense with the subjective moment of judgement complement one another: they are two aspects of the "bias" of automation.' (Andrejevic 2020a: 100) Offloading to technology is appealing in the context of political issues such as Trump, Brexit and the Covid19 pandemic, potentially leading to what Andrejevic describes as a post-political future.

It is a sign of the phenomenal success of the tech industries, the consolidation of the neoliberal mania for privatization, and the enabling response of the media that the commercial takeover of urban life seems like a natural next step for Silicon Valley. If there was once reluctance to let commercial platforms reconstruct pillars of civic life such as the public schools, now educational institutions embrace Facebook and Google as if they were public utilities. (Andrejevic 2020a: 108)

Such power in the hands of global platforms is our current reality as media platforms globally influence media censorship, governments, health care, education, and many more facets of public and private life (Greene 2018; York 2021). Sefton-Green and Pangrazio (2021) argue that datafication and automation in education reshape learning and raise additional obstacles for critical education as teachers and students become data subjects under the determination of preemption and algorithmic analysis removing the need or requirement for criticality, free-will, and identity. It is easy to see how the automation and pre-emption of the city can be applied and be part of other public and private spaces where no part of society is left unaffected, removing all frames and contexts as we move between our work, education, and civic lives. 


\section{Framelessness Removes Context}

Chapter 6, 'Framelessness', looks at the limits (or the lack thereof) to capture data on the whole of society i.e., Facebook building towards a Metaverse (Stokel-Walker 2022) and Amazon targeting total surveillance of society (Tuohy 2022). If we can collect enough data about society and individuals, some hold that we can 'work out' society and 'solve' social issues. The metaphor of the map is used by the author to describe how framelessness, all knowing data is not the same as lived experience and reality. 'A map that coincides with the territory is like a story that tries to tell everything all at once - that is, no story at all.' (Andrejevic 2020a: 113)

This sorting and correlation build a view that by collecting all of the data that 'there is' will result in an ultimate figuring out of society and the end of theory (Andersen 2008; Spinney 2022), thus making society machine readable. The Amazon Ring doorbell which creates a private network of surveillance for Amazon customers as well as backed (and used) by public policing (Selinger and Durant 2021) is a perfect example. This 'all seeing eye' can then be implemented by myriad private and public (many times blurring the line) organisations to sell products, educate and police.

Borrowing methods and methodologies from the natural and physical sciences to understand social worlds removes a sociological imagination (Mills 2000). This moves beyond a debate between positivism and interpretivism when automated technologies become operational in that they guide and make decisions for and about society, regarding politics and governance. Andrejevic (2020a: 114) concludes: 'When the world is platformed, the owners of the platform will rule the world.'

Andrejevic argues that frames are important in all aspects of life and they should be preserved rather than phased out by technology. For example, a comical and satirical piece on politics in a publication known for such satire would be out of place and interpreted differently in an academic book or mainstream news outlet. The frame is important because it gives borders and contexts to media and wider society. Andrejevic describes how automated media and those involved with its architecture are claiming that all frames and context can be removed for an ultimate '360-degree truth'. Critiques of such a position use underdetermination as an approach to critique the idea of a frameless all-knowing approach to research and society (Perrotta 2021; Stanford 2021). As Andrejevic (2020a: 124) states, 'the attempt to tell the story of everything ends in the undeniable and unusable conclusion that it is just incredibly complicated'.

Abstraction and theorising are required to try and understand our social and political worlds and are the foundation on which much of the social sciences and humanities are based. This, argues Andrejevic, is one of the reasons for the way that politicians and conspiracy theorists can so easily point to counter arguments as fake news rather than other sides of the story and alternative framings. Understanding the frames, contexts, and values of others is important to social cohesion and political action. Seeing beyond objective 'correct' or 'incorrect' is embraced by intercultural and cosmopolitan approaches (Appiah 2007) but rejected by frameless automation. 
Andrejevic is highly critical of such a frameless approach to society. However, a key debate and further work from a postdigital perspective could prove fruitful in taking critical perspectives to framelessness as a reaction to automated media. For example, when adopting a flat ontology between humans and technologies with actor-network theory, a key decision for researchers and practitioners (in many fields) is where does the frame begin and end in a sociology of assemblages between the human and non-human, space and time, analogue and digital, and disciplinary perspectives (Matthews 2019). The issue of frames is key for a future of blurring boundaries between human and non-human (Matthews 2020) and academic disciplines (Jandrić 2021).

A future of blurring boundaries between theory and practice, analog and digital, political and economic, and biological and digital (Peters et al. 2021) is described as the great convergence which lays out multidisciplinary, interdisciplinary, transdisciplinary, and antidisciplinary futures with analog-digital, physics-biology, and biology-information, resulting in new epistemologies, ontologies, and practices (Jandrić and Knox 2021). Jandrić and Knox describe our postdigital condition as requiring siloes to be removed and replaced by a convergence between analogue and the digital, biology and information, education, and the environment.

Andrejevic (2020a) shows us the importance of frames and the potential tyranny of framelessness, while the postdigital perspective shows us that we must broaden our perspectives for collective knowledge. The practical challenges summed up by Jandrić and Knox, 'balancing such a diverse body of insights is policy-makers worst nightmare' (2021: 9), show the appeal of automation. Such convergence and complexity require broader systems thinking (Buchanan 2019), and a critical look at frames provided by Andrejevic helps us to work through such issues and complexities in theory and practice.

Chapter 7 pulls together the overarching theme of removing subjectivity in a postsubjective future where the social world can be known in its entirety, frameless, and pre-empted. This goes as far as 'Automating desire' - which is the title of the chapter. Andrejevic continues the theme of an operational uncontested future which is objective without the need for political debate or discussion - or, in Silicon Valley language, 'frictionless' interactions with humans and machines. Another inconvenience for such smooth and post-subjective futures is the messiness and incompleteness of language and a move towards a much more operational way of communicating. 'The version of direct thought transmission anticipated by Zuckerberg embodies, somewhat paradoxically, the perfection of one-way transmission: the fantasy of a thought that allows for no external participation in its formation.' (Andrejevic 2020a: 134)

This links to the previous chapters in looking at social and political divisiveness in that engaging with others and their values and perspectives is a task which is not required in an envisioned automated future, where language is not precise or objective enough to achieve a smooth and frictionless post-subjective future. Referring back to a postdigital convergence (Peters et al. 2021), it can be argued that debate and conjecture are exactly what is required for more desirable and convivial futures. 


\section{The Question of What is Offloaded and Automated}

Automated Media (Andrejevic 2020a) is a timely publication when mainstream media and politics are predicting post-pandemic societal futures in the automated society of the so-called 'Fourth Industrial Era' (Bonilla-Molina 2020; Matthews et al. 2021). A key message from the book is that operationalising society in objective fashion in a post-subjective and post-political world is a threat to all aspects of life and democratic societies.

The word 'offload' and its derivatives are used by Andrejevic throughout the book. Key to automation, Andrejevic continually argues, is what are we prepared to offload to the non-human and who gets to decide what is offloaded. Importantly who gains and who loses out in such offloading is highly political and social but constantly depicted in wider discourse as apolitical, technological, and neutral.

While much of Automated Media feels dystopian, the only possible way forward for the author is a total rethink of media systems. 'Admitting this fact can have a dampening effect on hopes for change, but denying it renders change impossible.' (Andrejevic 2020a: 21) A key call to action from this message must be a democratic and nuanced conversation of what should and should not be offloaded to the automating algorithm with access to more and more data points. It is not being overly hyperbolic to say that leaving such decisions to unelected actors under the notion of apolitical efficiency and objectivity is a risk to all aspects of society.

\section{References}

Andersen, C. (2008). The End of Theory: The Data Deluge Makes the Scientific Method Obsolete. Wired, 23 June. https://www.wired.com/2008/06/pb-theory/. Accessed 17 January 2022.

Andrejevic, M. (2020a). Automated media. Abingdon and New York: Routledge.

Andrejevic, M. (2020b). The Digital Enclosure: A Response to Jill Walker Rettberg. The Digital Enclosure, 25 February. http://thedigitalenclosure.blogspot.com/2020/02/a-response-to-jill-walker-rettberg.html. Accessed 17 January 2022.

Appiah, A. (2007). Cosmopolitanism: Ethics in a world of strangers. New York: W. W. Norton \& Company.

Bonilla-Molina, L. (2020). Covid-19 on Route of the Fourth Industrial Revolution. Postdigital Science and Education, 2(3), 562-568. https://doi.org/10.1007/s42438-020-00179-4.

Buchanan, R. (2019). Systems Thinking and Design Thinking: The Search for Principles in the World We Are Making. She Ji: The Journal of Design, Economics, and Innovation, 5(2), 85-104. https://doi. org/10.1016/j.sheji.2019.04.001.

Gitelman, L. (Ed.). (2013). 'Raw data' is an oxymoron. Cambridge, MA: The MIT Press.

Greene, L. (2018). Silicon states: The power and politics of big tech and what it means for our future. Berkeley, CA: Counterpoint.

Jandrić, P. (2021). Biology, Information, Society. Postdigital Science and Education, 3(2), 261-265. https:// doi.org/10.1007/s42438-021-00220-0.

Jandrić, P., \& Knox, J. (2021). The postdigital turn: Philosophy, education, research. Policy Futures in Education, 147821032110627. https://doi.org/10.1177/14782103211062713.

Keynes, J. M. (2010). Economic Possibilities for Our Grandchildren. In J. M. Keynes, Essays in Persuasion (pp. 321-332). London: Palgrave Macmillan. https://doi.org/10.1007/978-1-349-59072-8_25.

Matthews, A. (2019). Design as a Discipline for Postdigital Learning and Teaching: Bricolage and Actor-Network Theory. Postdigital Science and Education, 1(2), 413-426. https://doi.org/10.1007/ s42438-019-00036-z. 
Matthews, A. (2020). Blurring boundaries between humans and technology: Postdigital, postphenomenology and actor-network theory in qualitative research. Qualitative Research in Sport, Exercise and Health, 13(1), 26-40. https://doi.org/10.1080/2159676X.2020.1836508.

Matthews, A. (2021). Death of the Lecture(r)? Postdigital Science and Education. https://doi.org/10. 1007/s42438-021-00239-3.

Matthews, A. M., McLinden, M., \& Greenway, C. (2021). Rising to the pedagogical challenges of the Fourth Industrial Age in the university of the future: An integrated model of scholarship. Higher Education Pedagogies, 6(1), 1-21. https://doi.org/10.1080/23752696.2020.1866440.

Mills, C. W. (2000). The sociological imagination. New York: Oxford University Press.

Noble, S. U. (2018). Algorithms of oppression: How search engines reinforce racism. New York: New York University Press.

Perrotta, C. (2021). Underdetermination, Assemblage Studies and Educational Technology: Rethinking Causality and Re-Energising Politics. Journal of New Approaches in Educational Research, 9(2), 43. https://doi.org/10.7821/naer.2021.1.638.

Peters, M. A., Jandrić, P., \& Hayes, S. (2021). Biodigital Philosophy, Technological Convergence, and Postdigital Knowledge Ecologies. Postdigital Science and Education, 3(2), 370-388. https://doi.org/ 10.1007/s42438-020-00211-7.

Rettberg, J. W. (2020). Book Review: Automated Media. Convergence: The International Journal of Research into New Media Technologies, 26(5-6), 1414-1417. https://doi.org/10.1177/1354856520906610.

Sefton-Green, J., \& Pangrazio, L. (2021). The death of the educative subject? The limits of criticality under datafication. Educational Philosophy and Theory. https://doi.org/10.1080/00131857.2021. 1978072.

Selinger, E., \& Durant, D. (2021). Amazon's Ring: Surveillance as a Slippery Slope Service. Science as Culture. https://doi.org/10.1080/09505431.2021.1983797.

Spinney, L. (2022). Are we witnessing the dawn of post-theory science? The Guardian, 9 January. https:// www.theguardian.com/technology/2022/jan/09/are-we-witnessing-the-dawn-of-post-theory-science. Accessed 17 January 2022.

Stanford, K. (2021). Underdetermination of Scientific Theory. In E. N. Zalta (Ed.), The Stanford Encyclopedia of Philosophy (Winter 2021). Stanford, CA: Stanford University. https://plato.stanford.edu/ archives/win2021/entries/scientific-underdetermination/. Accessed 17 January 2022.

Stokel-Walker, C. (2022). The metaverse: What is it, will it work, and does anyone want it? New Scientist, 5 February. https://www.newscientist.com/article/mg25333680-800-the-metaverse-what-is-itwill-it-work-and-does-anyone-want-it/. Accessed 17 January 2022.

Tuohy, J. P. (2022). Amazon introduces the Sidewalk Bridge Pro to expand the network. The Verge, 6 January. https://www.theverge.com/2022/1/6/22871031/amazon-launches-ring-sidewalk-bridge-pro. Accessed 17 January 2022.

Wajcman, J. (2017). Automation: Is it really different this time? The British Journal of Sociology, 68(1), 119-127. https://doi.org/10.1111/1468-4446.12239.

York, J. (2021). Silicon Values. London: Verso. 